Check for updates

Cite this: RSC Adv., 2018, 8, 29201

\title{
Dynamic corrosion behavior of superhydrophobic surfaces
}

\author{
C. Q. Li, M. Y. Zhu, J. F. Ou, (D) Y. L. Lu, F. J. Wang and W. Li*
}

For superhydrophobic surfaces immersed in water, a thin layer of air could be entrapped in the solid/liquid interface. This air may hinder the diffusion of dissolved corrosive species (such as $\mathrm{Cl}^{-}$ions in water) to the metallic substrate and, consequently, protect the metal from corrosion. However, in the dynamic water, the relative motion between the solid and the liquid would labilize the entrapped air and, consequently, decrease the corrosion resistance. In this work, to clarify the role of water flow velocity in such corrosion behavior, a superhydrophobic surface on aluminum substrates coded as $\mathrm{Al}-\mathrm{HCl}-\mathrm{H}_{2} \mathrm{O}-\mathrm{BT}-\mathrm{SA}$ was prepared by sequential treatment with $\mathrm{HCl}$, boiling water, bis- $(\gamma$-triethoxysilylpropyl)-tetrasulfide $(\mathrm{KH}$ $\mathrm{Si69}, \mathrm{BT}$ ) and stearic acid (SA). The contrast samples coded as Al- $\mathrm{HCl}-\mathrm{BT}-\mathrm{SA}, \mathrm{Al}-\mathrm{HCl}-\mathrm{H}_{2} \mathrm{O}-\mathrm{SA}$, and $\mathrm{Al}-$ $\mathrm{HCl}$-SA were also prepared similarly by omitting the treatment in boiling-water, the BT passivation, and the treatment in boiling-water/passivation by BT, respectively. These samples were then immersed into an aqueous solution of $\mathrm{NaCl}$ with different flow velocity $\left(0,0.5,1.0,1.5\right.$, and $\left.2.0 \mathrm{~m} \mathrm{~s}^{-1}\right)$, and its dynamic corrosion behavior was investigated. The results showed that, as the flow velocity increased, the corrosion resistance of the $\mathrm{Al}-\mathrm{HCl}-\mathrm{H}_{2} \mathrm{O}-\mathrm{BT}-\mathrm{SA}$ sample indeed deteriorated. However, compared with the contrast samples of $\mathrm{Al}-\mathrm{HCl}-\mathrm{BT}-\mathrm{SA}, \mathrm{Al}-\mathrm{HCl}-\mathrm{H}_{2} \mathrm{O}-\mathrm{SA}$, and $\mathrm{Al}-\mathrm{HCl}-\mathrm{SA}$, the deterioration in corrosion resistance for the $\mathrm{Al}-\mathrm{HCl}-\mathrm{H}_{2} \mathrm{O}-\mathrm{BT}-\mathrm{SA}$ sample was much lower, implying that the dynamic corrosion resistance of the superhydrophobic surfaces was closely related with the micro-structures and the organic passivated layers. The present study therefore provided a fundamental understanding for the applications of superhydrophobic samples to prevent the corrosion, especially, for various vessels in dynamic water.

Received 17th June 2018 Accepted 27th July 2018 DOI: $10.1039 / c 8$ ra05200j rsc.li/rsc-advances

\section{Introduction}

Aluminum (Al), with many advantages such as low density, good ductility, high strength, good heat/electric conductivity, etc., has been widely used in many fields such as electronics, aerospace, automobiles and so on. However, the application of Al is restricted because the $\mathrm{Al}$ surface often has localized corrosion in a medium of corrosive ions, such as $\mathrm{Cl}^{-}, \mathrm{F}^{-}, \mathrm{Br}^{-}, \mathrm{I}^{-}, \mathrm{NO}_{3}{ }^{-}$, $\mathrm{SCN}^{-}, \mathrm{ClO}_{3}{ }^{-}, \mathrm{ClO}_{4}{ }^{-}$, gluconate anions, and $\mathrm{H}^{+} \cdot{ }^{1-7}$ Nowadays, chromate conversion coating with the characteristics of easy application and effectiveness is one of the most used adhesion promoters to improve the corrosion resistance for $\mathrm{Al}^{8}{ }^{8}$ However, the hexavalent chromium compounds used in chromate conversion coating is known to be highly carcinogenic and strongly toxic., ${ }^{9,10}$

Based on the need of environment protection, silane agents were applied as an alternative for chromates in the metal pretreatment industry. ${ }^{11,12}$ The silane agents with the hydrolysable alkoxy groups, such as $\mathrm{Si}-\mathrm{OMe}$ and $\mathrm{Si}-\mathrm{OEt}$, undergo a hydrolysis process to produce silanols $(\mathrm{Si}-\mathrm{OH})$. Then, the $\mathrm{Si}-$

School of Materials and Engineering, Jiangsu University of Technology, Changzhou 213001, P. R. China. E-mail: oujunfei_1982@163.com
$\mathrm{OH}$ group can interact with the $\mathrm{Al}-\mathrm{OH}$ group on the hydrated $\mathrm{Al}$ surface via the hydrogen bond. During the further thermal treatment, such bonds may convert to $\mathrm{Al}-\mathrm{O}-\mathrm{Si}$ and the silanes attach to the $\mathrm{Al}$ surface firmly. The excess $\mathrm{Si}-\mathrm{OH}$ groups condense among themselves to form a siloxane network (Si-O$\mathrm{Si}$ ), which resists to aggressive species. However, the so-formed $\mathrm{Al}-\mathrm{O}-\mathrm{Si}$ and $\mathrm{Si}-\mathrm{O}-\mathrm{Si}$ bonds were susceptible to hydrolysis at high $\mathrm{pH}$ and the hydrolytic stability of these bonds was close to the molecular structures, such as the length of the alkyl chains ${ }^{13}$ and the type of terminal groups. ${ }^{14-16}$

Herein, a bis-silane, bis-( $\gamma$-triethoxysilylpropyl)-tetrasulfide (KH-Si69, BT), was used. Besides the hydrolysable alkoxy tail and head groups, the -S-S-S-S- group in the middle of the chain was able to enhance the hydrophobicity of the film, postponing water penetration during immersion process. To further improve the corrosion resistance of the BT films, many efforts have been made by adding dopants, such as rare earth cations $^{17-19}$ and nanoparticles. ${ }^{20-22}$ Herein, we use another different way, viz., constructing a hydrophobic outerlayer (stearic acid, SA) onto the BT film. To the best of our knowledge, it is not easy to graft the SA molecules to the hydrophobic BT film. However, the so-formed BT film without thermal 
treatment is hydrophilic with outer exposed $\mathrm{Si}-\mathrm{OH}$ groups, which serve as the active sites to anchor the SA molecules [Fig. 1(II)].

On a rough-structured Al surface, we even obtained a BT-SA bilayer superhydrophobic film (abridged as SHF). As well known, the SHF is repellent to water with high water contact angle above $150^{\circ}$ and sliding angle below $10^{\circ} \cdot{ }^{23-26}$ Once the SHF is immersed into water, a layer of air will be entrapped in the solid/liquid interface, which can hinder the penetration of corrosive species (such as the $\mathrm{Cl}^{-}$ions dissolved in water) to reach the metallic substrate and improve the corrosion resistance greatly. ${ }^{27-31}$ However, such studies ${ }^{20-24}$ were performed in the static aqueous solution. In the dynamic aqueous solution, the entrapped air on the SHF would be squeezed out much more easily and the longetivity of the entrapped air would be shortened to some extent. Correspondingly, the corrosion resistance due to the entrapped air would be weakened. Herein, to verify these assumptions, for the first time, the corrosion resistance of the so-obtained BT-SA SHF in the dynamic $\mathrm{NaCl}$ aqueous solution is investigated. It is expected that the present study can provide a fundamental understanding for the applications of superhydrophobic surfaces to prevent the corrosion, especially, for various vessels in dynamic water.

\section{Experimental}

\subsection{Sample preparations}

The Al was firstly ground with abrasive papers (600 \# and 2000 \#) and then ultrasonically cleaned in ethanol for $10 \mathrm{~min}$. Then, the $\mathrm{Al}$ sample was treated sequentially by $\mathrm{HCl}$, boiling water, bis- $(\gamma-$ triethoxysilylpropyl)-tetrasulfide (KH-Si69, BT) and stearic acid (SA). The fabrication details and possible mechanisms were shown in Fig. 1. For convenience, the so-obtained sample was coded as Al- $\mathrm{HCl}-\mathrm{H}_{2} \mathrm{O}-\mathrm{BT}-\mathrm{SA}$. The fabrication procedure of the
(I)

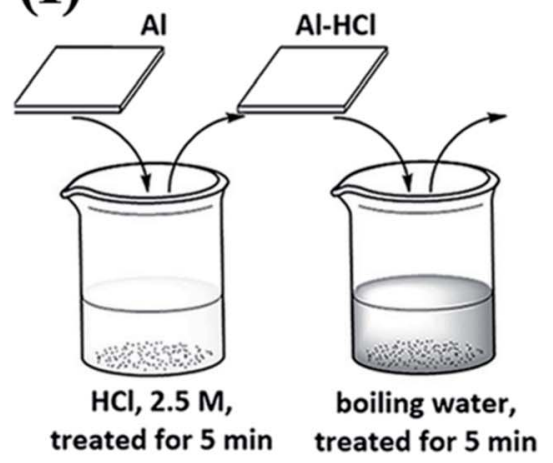

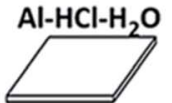

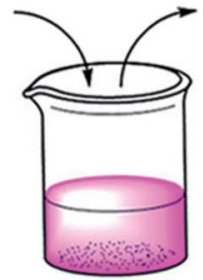

BTESPT ( 5 vol. \%) in a mixture of water (5 vol. \%) and ethanol (90 vol. \%), prehydrolyzed for $36 \mathrm{~h}$; immersed in for $10 \mathrm{~min}$

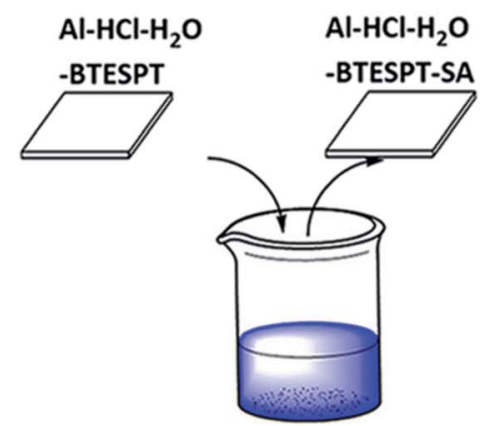

Stearic acid in ethanol, $1.0 \mathrm{wt}$. \%; immersed in for $\mathbf{3 0} \mathrm{min}$; then taken out and heated at $120 \mathrm{C}$ for $1 \mathrm{~h}$
(II) (a) hydrolyzing of the BTESPT

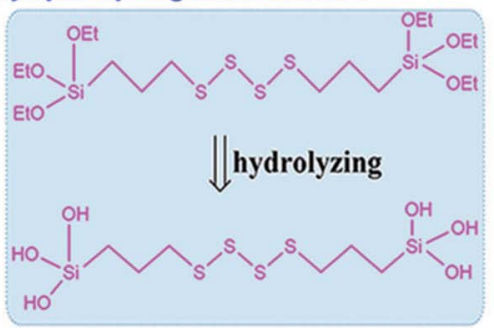

(b) possible interaction between the hydrolyzed BTESPT and the Al surface

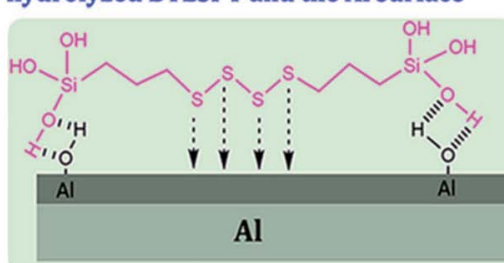

(c) possible interaction between the stearic acid the attached BTESPT (d) possible interlayer interaction for the Al-HCl-H2O-BTESPT sample

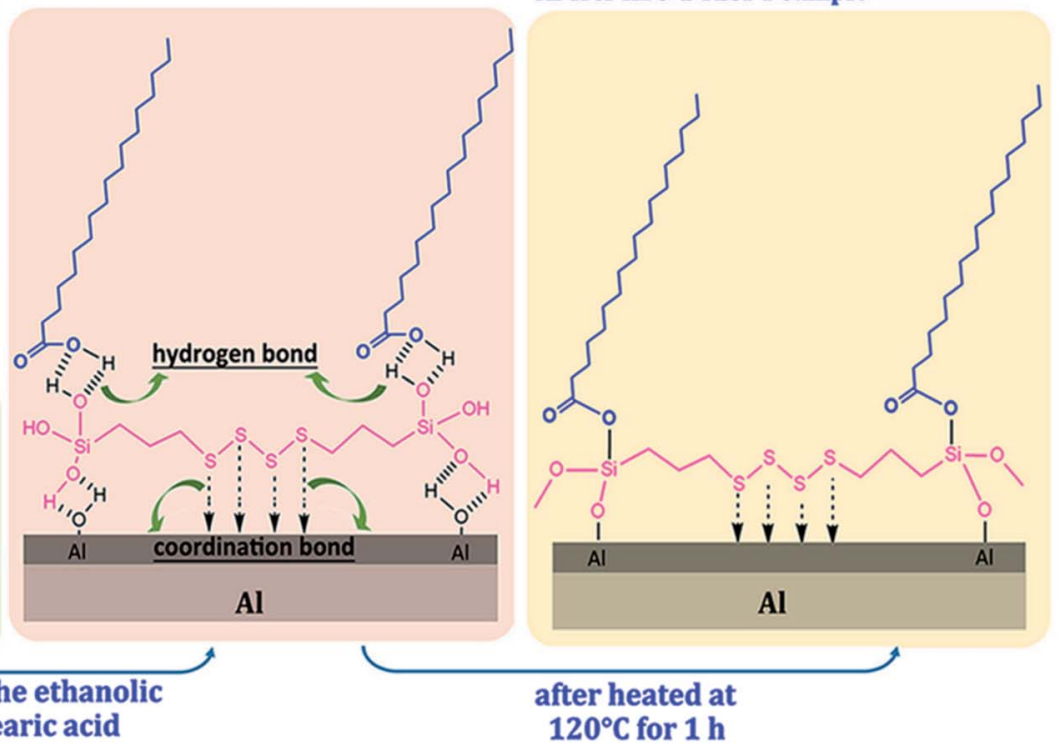

Fig. 1 (I) The fabrication process of the Al- $\mathrm{HCl}-\mathrm{H}_{2} \mathrm{O}-\mathrm{BT}-\mathrm{SA}$ sample; (II) possible mechanism for the formation of different samples. 
contrast superhydrophobic samples was the same but certain treatment was omitted. For instance, the treating in boilingwater and the BT passivation was omitted for the $\mathrm{Al}-\mathrm{HCl}-\mathrm{BT}-$ SA sample and the Al-HCl- $\mathrm{H}_{2} \mathrm{O}-\mathrm{BT}-\mathrm{SA}$ sample. For the Al-HClSA sample, both the treating in boiling-water and the passivation by BT was omitted.

\subsection{Sample characterizations}

An optical contact angle meter (Easydrop, Krüss, Germany) with a computer controlled liquid dispensing system and a motorized tilting stage was used to measure the contact angle at room temperature $\left(25^{\circ} \mathrm{C}\right)$ with ultrapure water $(7 \mu \mathrm{L})$. The average contact angle values were obtained by measuring the sample at 5 different positions of the substrate. The morphological microstructures were observed on field emission scanning electron microscope (FE-SEM, JSM-6701F) under vacuum environment and the chemical compositions were characterized by energy dispersive X-ray spectroscopy (EDS, INCA 250, Oxford, UK). The surface chemical compositions was also measured by the X-ray photoelectron spectroscopy (XPS, Physical Electronics, PHI-5702, USA). Average thickness of the so-generated hydroxide in boiling water was measured by a DEKTAK-150 step profiler (Veeco Instruments Inc., United States) at 5 different positions. The measurements were performed using a monochromated $\mathrm{Al}-\mathrm{K} \alpha$ irradiation and the chamber pressure was about $3 \times 10^{-8}$ torr under testing condition. The binding energy of adventitious carbon (C1s: $284.8 \mathrm{eV}$ ) was used as a basic reference. The corrosion resistance in the $\mathrm{NaCl}$ aqueous solution $(3.5 \mathrm{wt} \%)$ was evaluated by monitoring the change in surface wettability, surface morphology, and surface chemistry.

\section{Results and discussion}

\subsection{Surface morphology, chemistry, and wettability}

After chemically etched by $\mathrm{HCl}$, micro-steps were formed on the surface [Fig. 2(a)]. As explained by Shen et al., the formation of such micro-steps was due to the dislocation defects in the $\mathrm{Al}$ substrate with relatively higher energy, which were prone to be dissolved under the attack of chemical etchants, such as $\mathrm{HCl}^{32}$ Due to the capillary effect, the so-formed $\mathrm{Al}-\mathrm{HCl}$ sample was superhydrophilic (Table 1, sample a). After surface passivation by stearic acid (SA), the Al-HCl-SA sample turned to be superhydrophobic (Table 1, sample e). As discovered by Zhou et al., the superhydrophobicity can further be enhanced by the nanostructures on the micro-steps. ${ }^{33}$ So, the Al-HCl sample was transferred into the boiling water to generate nano-flakes [Fig. 2(d)] and the so-formed sample was coded as Al-HCl$\mathrm{H}_{2} \mathrm{O}$. The optimal treating time in the boiling water to form the nano-flakes was determined to be $5 \mathrm{~min}$. As the treating time prolonging to $10 \mathrm{~min}$ [Fig. 2(e)] or $15 \mathrm{~min}$ [Fig. 2(f)], some nanoflakes agglomerated and the sliding angle increased to $15.2 \pm$ $1.2^{\circ}$ or $25.1 \pm 1.5^{\circ}$ (Table 1 , sample $\mathrm{g}$ ). In the following text, if there is no other special instruction, the treating time in the boiling water for the $\mathrm{Al}-\mathrm{HCl}-\mathrm{H}_{2} \mathrm{O}$ sample and its derivatives was $5 \mathrm{~min}$. As revealed in our previous study ${ }^{34}$ and other research, ${ }^{35}$ the so-formed nano-flakes are hydroxide of $\mathrm{AlO}(\mathrm{OH})$, which can serve as the barrier layer to improve the corrosion resistance. The thickness of the so-formed nano-flakes was determined to be $205 \pm 25 \mathrm{~nm}$ by a step profiler.

The $\mathrm{AlO}(\mathrm{OH})$ species are abundant with hydroxyl groups, which may facilitate the anchoring of silanes, such as the bis- $(\gamma$ triethoxysilylpropyl)-tetrasulfide (BT). As revealed in other research, ${ }^{35}$ the so-hydrolyzed $\mathrm{BT}$ is attached to the $\mathrm{Al}$ (110) surface via the chemical adsorption of the sulfur atoms with the aluminum ones and the hydrogen bonding between the soformed $\mathrm{Si}-\mathrm{OH}$ and the Al-OH bonding [Fig. 1(II)(b)]. However, it is supposed that only one out of three $\mathrm{Si}-\mathrm{OH}$ bonding is interacted with the substrate; the other two are exposed outside. This suggests that there are some $\mathrm{Si}-\mathrm{OH}$ groups on the surface; consequently, the $\mathrm{Al}-\mathrm{HCl}-\mathrm{H}_{2} \mathrm{O}-\mathrm{BT}$ sample is hydrophilic with the contact angle of $62.8 \pm 1.5^{\circ}$ (Table 1, sample c). Under further annealing, the outer exposed $\mathrm{Si}-\mathrm{OH}$ groups may turn into the $\mathrm{Si}-\mathrm{O}-\mathrm{Si}$ ones and the surface was dominated by the groups with low-surface-energy, such as $-\mathrm{CH}_{2}-$ and $-\mathrm{S}-\mathrm{S}-\mathrm{S}-\mathrm{S}-$. Thus, the contact angle and sliding angle of the annealed Al-
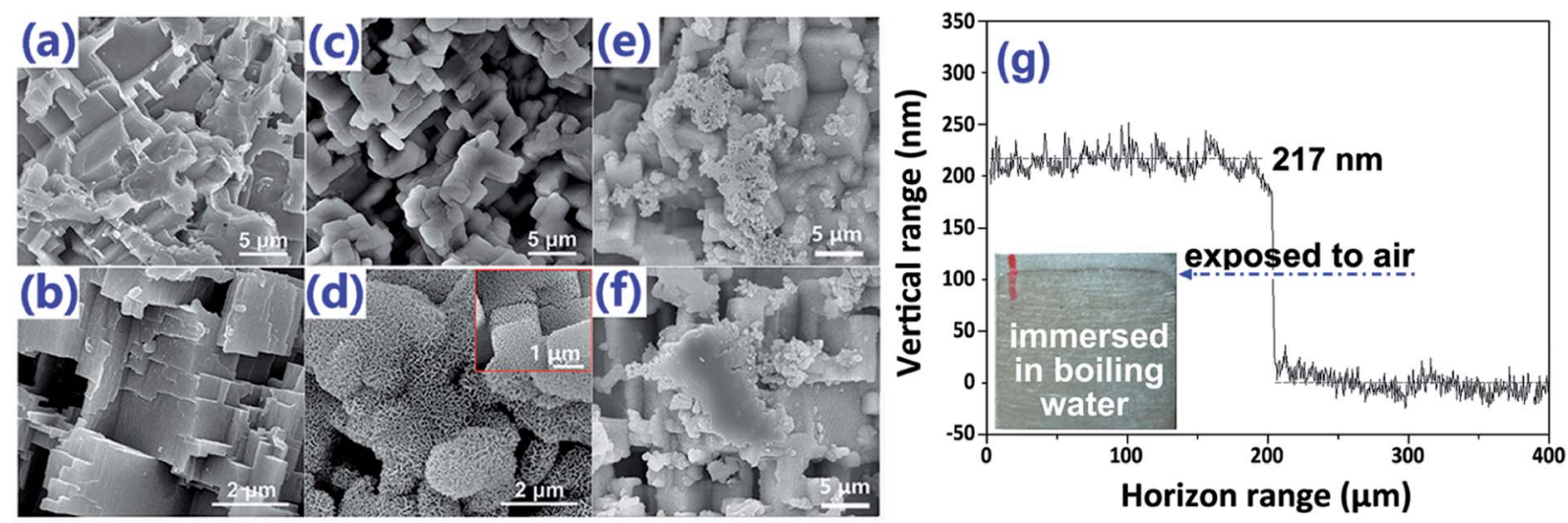

Fig. 2 Surface morphology for the $\mathrm{Al}-\mathrm{HCl}$ sample ( $\mathrm{a}$ and $\mathrm{b}$ ) and the $\mathrm{Al}-\mathrm{HCl}-\mathrm{H}_{2} \mathrm{O}$ sample (d-f). For (c) and (d), the treating time in the boiling water is $5 \mathrm{~min}$; for (e) and (f), the treating time in the boiling water is $10 \mathrm{~min}$ and $15 \mathrm{~min}$, respectively. One dimensional surface shape across the boundary of the boiling water treated and non-treated area (g); the measurements were performed at five different lines and the average thickness of the hydroxide was $205 \pm 25 \mathrm{~nm}$. 
Table 1 Surface wettability for different samples

\begin{tabular}{|c|c|c|}
\hline Sample & Water contact angle (deg) & Sliding angle (deg) \\
\hline $\mathrm{a}, \mathrm{Al}-\mathrm{HCl}$ & $\sim 0$ & - \\
\hline $\mathrm{b}, \mathrm{Al}-\mathrm{HCl}-\mathrm{H}_{2} \mathrm{O}$ & $\sim 0$ & - \\
\hline $\mathrm{d}, \mathrm{Al}-\mathrm{HCl}-\mathrm{H}_{2} \mathrm{O}-\mathrm{BT}-\mathrm{SA}^{b}$ & $167.9 \pm 1.8 / 161.3 \pm 1.6$ & $3.6 \pm 0.5 / 9.5 \pm 1.2$ \\
\hline e, Al-HCl-SA & $166.3 \pm 1.5$ & $6.8 \pm 0.8$ \\
\hline f, Al-HCl-BT-SA & $166.6 \pm 1.9$ & $7.2 \pm 0.8$ \\
\hline
\end{tabular}

${ }^{a}$ The former and latter value is for the unannealed and annealed sample, respectively. ${ }^{b}$ The former and latter value is for the sample prepared by immersing the unannealed and annealed Al- $\mathrm{HCl}-\mathrm{H}_{2} \mathrm{O}-\mathrm{BT}$ sample into the stearic acid, respectively, and then annealed at $120{ }^{\circ} \mathrm{C} .{ }^{c}$ The first, second, and third value is for the $\mathrm{Al}-\mathrm{HCl}-\mathrm{H}_{2} \mathrm{O}$ sample with a treating time in the boiling water of $5 \mathrm{~min}, 10 \mathrm{~min}$, and 15 min, respectively.

$\mathrm{HCl}-\mathrm{H}_{2} \mathrm{O}-\mathrm{BT}$ sample turned to be approx. $155.7^{\circ}$ and approx. $14.5^{\circ}$, respectively (Table 1 , sample c). Moreover, under annealing, the hydrogen bonding between the $\mathrm{Al}-\mathrm{OH}$ group and the $\mathrm{Si}-\mathrm{OH}$ group may also converted into the $\mathrm{Al}-\mathrm{O}-\mathrm{Si}$ chemical bonding, ${ }^{36,37}$ and the BT molecules are attached to the substrate more firmly. To prove this assumption, the annealed and the unannealed $\mathrm{Al}-\mathrm{HCl}-\mathrm{H}_{2} \mathrm{O}-\mathrm{BT}$ samples were immersed into the ethanol under ultrasonication and the variation of surface wettability was monitored (Fig. 3). After $20 \mathrm{~min}$, the contact angle for the unannealed $\mathrm{Al}-\mathrm{HCl}-\mathrm{H}_{2} \mathrm{O}-\mathrm{BT}$ sample (curve $\mathrm{d}$ in Fig. 3) decreased sharply to approx. $5^{\circ}$ and the annealed sample (curve c in Fig. 3) still possessed a contact angle above $150^{\circ}$.

We also performed a contrast experiment to infer that the exposed $\mathrm{Si}-\mathrm{OH}$ groups on the un-annealed $\mathrm{Al}-\mathrm{HCl}-\mathrm{H}_{2} \mathrm{O}-\mathrm{BT}$ sample were essential for the anchoring of SA. The (Al-HCl$\left.\mathrm{H}_{2} \mathrm{O}-\mathrm{BT}\right)_{\mathrm{an}}$-SA sample was prepared by immersing the annealed $\mathrm{Al}-\mathrm{HCl}-\mathrm{H}_{2} \mathrm{O}-\mathrm{BT}$ sample without $\mathrm{Si}-\mathrm{OH}$ groups into the ethanol solution of SA and then annealed at $120^{\circ} \mathrm{C}$. The so-obtained (Al$\left.\mathrm{HCl}-\mathrm{H}_{2} \mathrm{O}-\mathrm{BT}\right)_{\mathrm{an}}-\mathrm{SA}$ sample possessed a high contact angle of $161.3 \pm 1.6^{\circ}$ and low sliding angle of $9.5 \pm 1.2^{\circ}$ (the latter data for sample d in Table 1), which were superior to the data (155.7 $\pm 1.6^{\circ}$ and $14.5 \pm 0.9^{\circ}$, the latter data for sample $\mathrm{c}$ in Table 1 ) for the annealed $\mathrm{Al}-\mathrm{HCl}-\mathrm{H}_{2} \mathrm{O}-\mathrm{BT}$ sample, however, still inferior to the data $\left(167.9 \pm 1.8^{\circ}\right.$ and $3.5 \pm 0.5^{\circ}$, the former data for sample $\mathrm{d}$ in Table 1) for the Al-HCl- $\mathrm{H}_{2} \mathrm{O}-\mathrm{BT}-\mathrm{SA}$ sample. Although the superhydrophobicity was achieved for the $\left(\mathrm{Al}-\mathrm{HCl}-\mathrm{H}_{2} \mathrm{O}-\mathrm{BT}\right)_{\mathrm{an}^{-}}$
SA sample, the anchoring of SA molecules to the (Al- $\mathrm{HCl}-\mathrm{H}_{2} \mathrm{O}-$ $\mathrm{BT})_{\text {an }}$ surface was supposed to be weak and would be detached easily. To confirm this, the (Al- $\left.\mathrm{HCl}-\mathrm{H}_{2} \mathrm{O}-\mathrm{BT}\right)_{\mathrm{an}}-\mathrm{SA}$ sample (curve b in Fig. 3) was ultrasonicated in ethanol. After merely 20 min ultrasonication in ethanol, the curves for samples of the $\left(\mathrm{Al}-\mathrm{HCl}-\mathrm{H}_{2} \mathrm{O}-\mathrm{BT}\right)_{\text {an }}$ and $\left(\mathrm{Al}-\mathrm{HCl}-\mathrm{H}_{2} \mathrm{O}-\mathrm{BT}\right)_{\mathrm{an}}-\mathrm{SA}$ almost overlapped. This happened because the SA molecules were removed from the (Al- $\left.\mathrm{HCl}-\mathrm{H}_{2} \mathrm{O}-\mathrm{BT}\right)_{\mathrm{an}}-\mathrm{SA}$ sample and its wettability was similar to that of the (Al-HCl- $\left.\mathrm{H}_{2} \mathrm{O}-\mathrm{BT}\right)_{\text {an }}$ sample. However, for the $\mathrm{Al}-\mathrm{HCl}-\mathrm{H}_{2} \mathrm{O}-\mathrm{BT}-\mathrm{SA}$ sample, the interaction between the BT layer and the SA molecules was supposed to be the covalent $\mathrm{C}-$ O-Si bonding (Fig. 1(II)d), so the Al-HCl- $\mathrm{H}_{2} \mathrm{O}-\mathrm{BT}-\mathrm{SA}$ sample (curve a in Fig. 3) possessed much better excellent durability against the ultrasonication as compared with the $\left(\mathrm{Al}-\mathrm{HCl}-\mathrm{H}_{2} \mathrm{O}-\right.$ BT) ${ }_{\mathrm{an}}$-SA sample (curve b in Fig. 3).

The surface chemistry of the samples was evaluated by XPS. For the $\mathrm{Al}-\mathrm{HCl}$ sample, the $\mathrm{Al}$ (III) signal in the $\mathrm{Al} 2 \mathrm{p}$ spectrum [Fig. 4(II)(a)] was unexpectedly visible. It was supposed that, in the aqueous solution of $\mathrm{HCl}$, the oxide layer would be eliminated through the chemical reaction as shown in eqn (1). Thus, there should have been no oxide species and the related $\mathrm{Al}$ (III) signal. However, once the Al-HCl sample was taken out and exposed to the air, the outermost $\mathrm{Al}(0)$ species would be oxidized into $\mathrm{Al}_{2} \mathrm{O}_{3}$ easily (eqn (2)). Consequently, the $\mathrm{Al}$ (III) signal emerged. The visible $\mathrm{Al}$ (0) signal in Fig. 4(II)(a) also suggested that the newly-formed oxide layer was thin and the
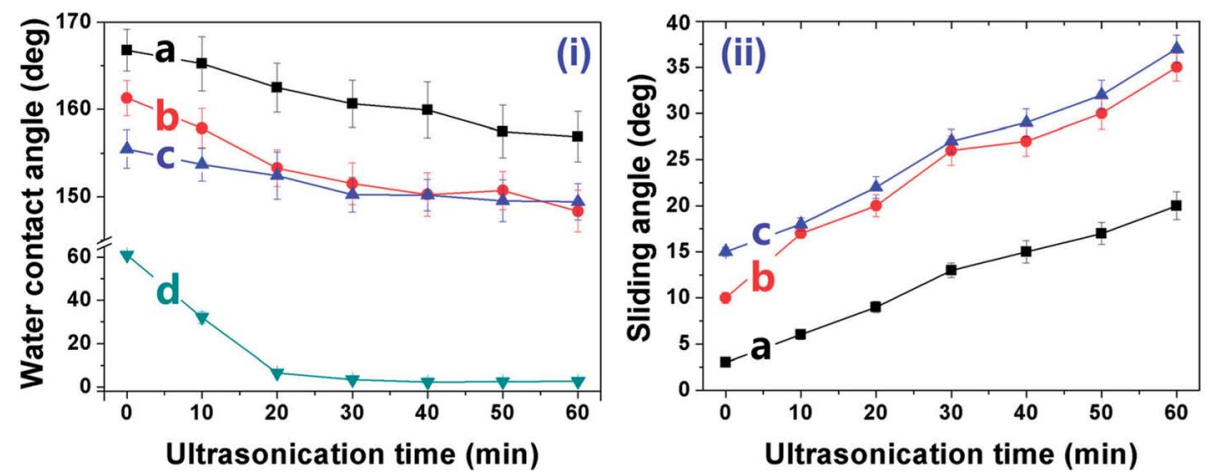

Fig. 3 Variation of water contact angle and sliding angle against ultrasonication time in ethanol for the Al- $\mathrm{HCl}-\mathrm{H}_{2} \mathrm{O}-\mathrm{BT}-\mathrm{SA}$ sample (a), the (Al$\left.\mathrm{HCl}-\mathrm{H}_{2} \mathrm{O}-\mathrm{BT}\right)_{a n}-\mathrm{SA}$ sample (b), the $\mathrm{Al}-\mathrm{HCl}-\mathrm{H}_{2} \mathrm{O}-\mathrm{BT}$ sample (c), and the unannealed $\mathrm{Al}-\mathrm{HCl}-\mathrm{H}_{2} \mathrm{O}-\mathrm{BT}$ sample (d). 

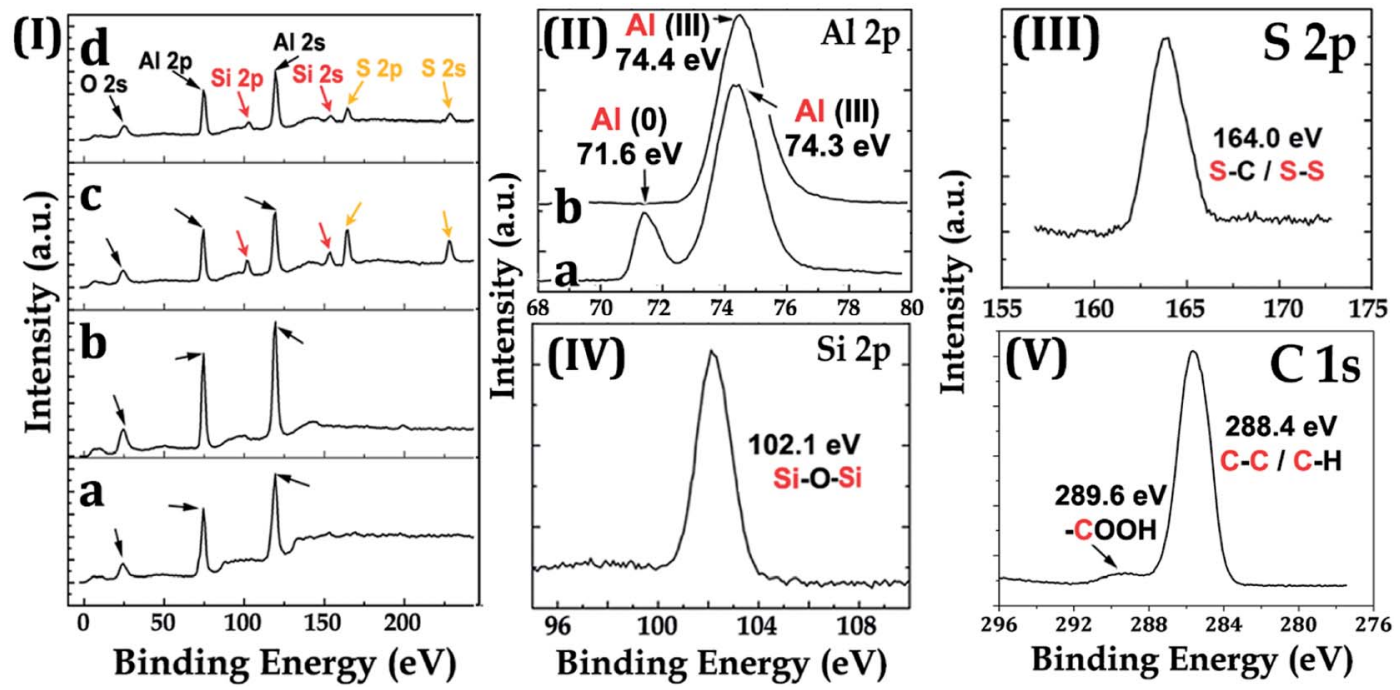

Fig. 4 X-ray photoelectron spectra for the $\mathrm{Al}-\mathrm{HCl}$ sample (I)-(a), (II)-(a), the $\mathrm{Al}-\mathrm{HCl}-\mathrm{H}_{2} \mathrm{O}$ sample (I)-(b), (II)-(b), the Al-HCl-H $\mathrm{O}-\mathrm{BT}(\mathrm{I})-(\mathrm{c})$, (III), (IV), and the Al-HCl- $\mathrm{H}_{2} \mathrm{O}-\mathrm{BT}-\mathrm{SA}$ sample (I)-(d), (V).

$\mathrm{Al}(0)$ beneath it was still detectable. For the Al-HCl- $\mathrm{H}_{2} \mathrm{O}$ sample, as revealed in other research, ${ }^{21-23}$ the boehmite of $\mathrm{AlO}(\mathrm{OH})$ was formed through the chemical reactions as shown in eqn (3).

Elimination of oxide by

$$
\mathrm{HCl}: \mathrm{Al}_{2} \mathrm{O}_{3}+6 \mathrm{HCl} \rightarrow 2 \mathrm{AlCl}_{3}+3 \mathrm{H}_{2} \mathrm{O}
$$

Formation of oxide in the air :

$$
4 \mathrm{Al}(0)+6 \mathrm{O}_{2} \rightarrow 2 \mathrm{Al}_{2} \mathrm{O}_{3}
$$

Formation of boehmite in the boiling water :

$$
\begin{aligned}
& 2 \mathrm{Al}+(x+3) \mathrm{H}_{2} \mathrm{O} \rightarrow \mathrm{Al}_{2} \mathrm{O}_{3} x \mathrm{H}_{2} \mathrm{O}+3 \mathrm{H}_{2} \uparrow \\
& \mathrm{Al}_{2} \mathrm{O}_{3} x \mathrm{H}_{2} \mathrm{O} \rightarrow 2 \mathrm{AlO}(\mathrm{OH})+(x-1) \mathrm{H}_{2} \mathrm{O}
\end{aligned}
$$

For the Al-HCl- $\mathrm{H}_{2} \mathrm{O}-\mathrm{BT}$ sample, $\mathrm{Si} 2 \mathrm{~s} / 2 \mathrm{p}$ and S 2s/2p peaks attributed to the $\mathrm{Si}$ and $\mathrm{S}$ atoms, respectively, in the BT molecules were observed. For the Al-HCl- $\mathrm{H}_{2} \mathrm{O}-\mathrm{BT}-\mathrm{SA}$ sample, the C 1s spectrum showed a small peak at $289.6 \mathrm{eV}$, which was attributed to the $-\mathrm{COOH}$ group in the SA molecule. Moreover, due to the overlayed SA molecules, the peaks originated from BT sublayer became weaker, however, still visible [comparing the related peaks in Fig. 4(I)(c) and (I)(d)].

\subsection{Corrosion resistance in the $\mathrm{NaCl}$ solution}

To evaluate the corrosion resistance, the variation in surface wettability (Fig. 5), surface morphology (Fig. 5), and surface chemistry (Table 2) was monitored. As shown in Fig. 5(a3), after only 2 days in the static $\mathrm{NaCl}$ aqueous solution, the sliding angle for the Al-HCl-SA sample increased to $90^{\circ}$. In this condition, the water droplet adhered to the surface firmly even when the sample was laid vertically or upside-down. Once the BT interlayer was added, the time taken for the sliding angle increasing to $90^{\circ}$ prolonged to 4 days [(Fig. 5(b3))]. For the Al$\mathrm{HCl}-\mathrm{H}_{2} \mathrm{O}-\mathrm{SA}$ sample, the corresponding time prolonged largely to 16 days [(Fig. 5(c3))]. For the Al-HCl- $\mathrm{H}_{2} \mathrm{O}-\mathrm{BT}-\mathrm{SA}$ sample, even after 18 days, the contact angle was still as high as $152.3 \pm$ $2.8^{\circ}$ and the sliding angle was $49.0 \pm 2.5^{\circ}[($ Fig. $5(\mathrm{~d} 3))]$. The surface morphology for different samples after static corrosion for 18 days was also examined by FE-SEM. For the Al-HCl-SA sample [Fig. 5(a1) and (a2)], the nano-flakes became compacted and lots of micro-sheets were formed atop. For the Al-HCl-BTSA sample [Fig. 5(b1) and (b2)], fewer micro-sheets were observed as compared with the Al-HCl-SA sample. For the Al$\mathrm{HCl}-\mathrm{H}_{2} \mathrm{O}-\mathrm{SA}$ sample, only some compact micro-structures instead of the micro-sheets were observed (as indicated by the yellow arrows in Fig. 5(c1). Under higher magnification, it was clearly observed that the nano-flakes on a micro-step became compacted (as indicated by the yellow arrows in Fig. 5(c2)). For the Al-HCl- $\mathrm{H}_{2} \mathrm{O}-\mathrm{BT}-\mathrm{SA}$ sample, the change in surface morphology was so slight and we could not tell the difference between Fig. 5(d2) and 2(d). So, we could say that the Al-HCl$\mathrm{H}_{2} \mathrm{O}-\mathrm{BT}-\mathrm{SA}$ sample possessed the best corrosion resistance in the static $\mathrm{NaCl}$ aqueous solution.

Similarly, the corrosion resistance in the dynamic $\mathrm{NaCl}$ aqueous solution was also estimated by monitoring the variation in surface wettability (Fig. 6a-d) and surface morphology (Fig. 6e). It was obvious that, as the velocity of water flow increased from $0.5 \mathrm{~m} \mathrm{~s}^{-1}$ to $2.0 \mathrm{~m} \mathrm{~s}^{-1}$, the deterioration of superhydrophobicity became faster (Fig. 6a-d). In other words, as the flow velocity increased, the water contact angle decreased and the sliding angle increased more quickly. This phenomenon could be well understood if one noticed that, in the dynamic $\mathrm{NaCl}$ aqueous solution, an impact proportional to the flow velocity as shown in Fig. $6 \mathrm{f}$ would be formed on the uneven solid surface. The so-formed impact would accelerate the expellation of trapped air from the water/solid interface and the transition from Cassie wetting state to Wenzel state. In the Wenzel wetting state, the $\mathrm{NaCl}$ aqueous solution was in contact with the aluminum directly; consequently, the corrosion was more seriously and the deterioration of superhydrophobicity 

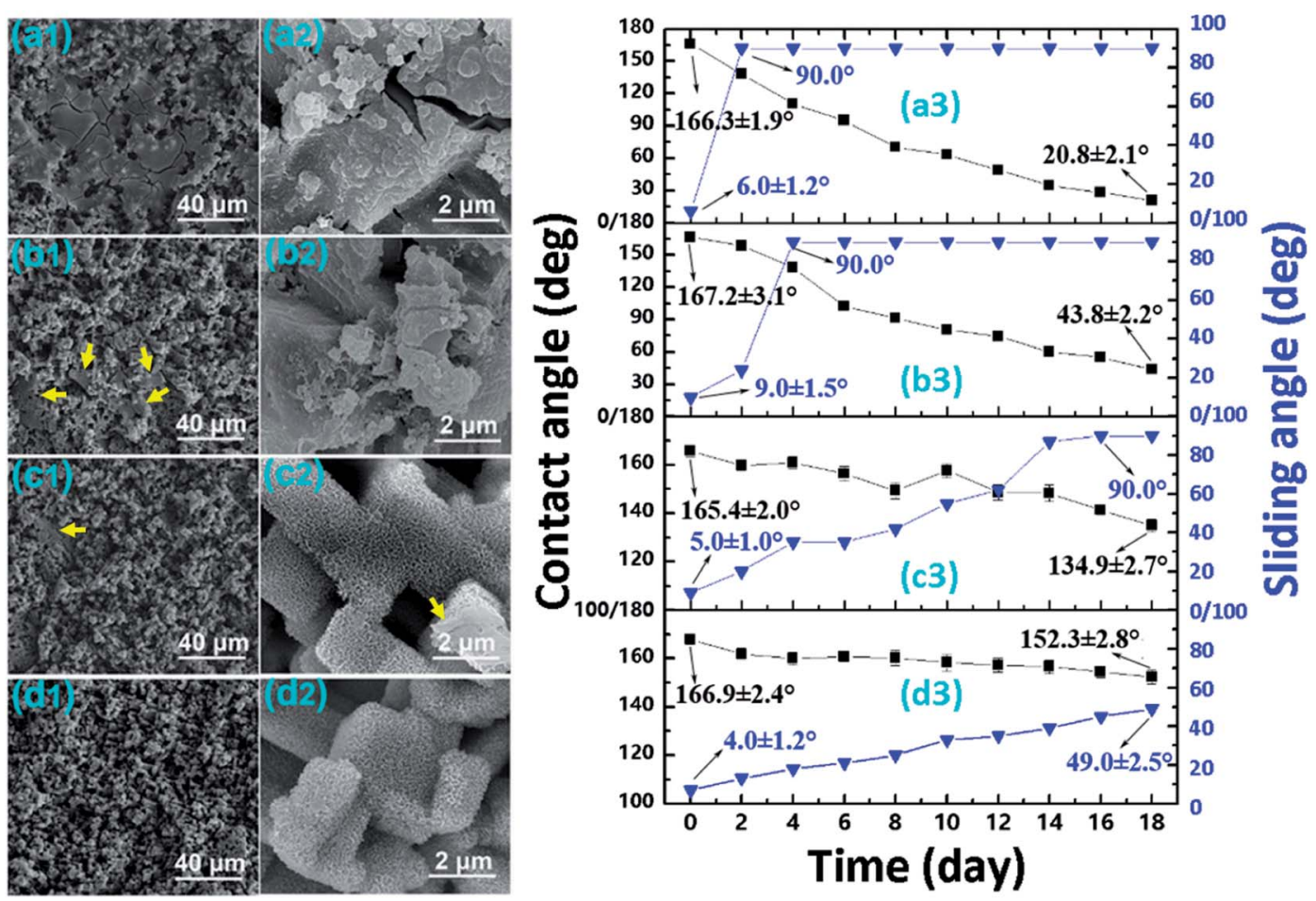

Fig. 5 Surface morphology for different sample ((a), the Al-HCl-SA sample; (b), the Al-HCl-BT-SA sample; (c), the Al-HCl-H ${ }_{2} \mathrm{O}-\mathrm{SA}$ sample; (d), the $\mathrm{Al}-\mathrm{HCl}-\mathrm{H}_{2} \mathrm{O}-\mathrm{BT}-\mathrm{SA}$ sample) in the static $\mathrm{NaCl}$ aqueous solution for 18 days and variation of surface wettability against immersion time.

Table 2 Content ratio of oxygen to aluminum before and after corrosion (viz., $R_{[\mathrm{O}] /[\mathrm{A}], \mathrm{bc}}$ and $\left.R_{[\mathrm{O}] /[\mathrm{Al}], \mathrm{ac}}\right)$ and the increasing ratio (IR) calculated by the eqn (7)

\begin{tabular}{|c|c|c|c|c|c|}
\hline \multirow[b]{2}{*}{ Sample } & \multirow[b]{2}{*}{$R_{[\mathrm{O}] /[\mathrm{Al}], \mathrm{bc}}$} & \multicolumn{2}{|c|}{$\begin{array}{l}\text { Static corrosion, } \\
18 \mathrm{~d}\end{array}$} & \multicolumn{2}{|c|}{$\begin{array}{l}\text { Dynamic } \\
\text { corrosion, } \\
2.0 \mathrm{~m} \mathrm{~s}^{-1}, 50 \mathrm{~h}\end{array}$} \\
\hline & & $R_{[\mathrm{O}] /[\mathrm{Al}], \mathrm{ac}}$ & IR & $R_{[\mathrm{O}] /[\mathrm{Al}], \mathrm{ac}}$ & IR \\
\hline Al-HCl-SA & 0.05 & 1.49 & $2880.0 \%$ & 0.49 & $880.0 \%$ \\
\hline Al-HCl-BT-SA & 0.07 & 0.94 & $1242.9 \%$ & 0.42 & $500.0 \%$ \\
\hline $\mathrm{Al}-\mathrm{HCl}-\mathrm{H}_{2} \mathrm{O}-\mathrm{SA}$ & 0.73 & 1.15 & $57.5 \%$ & 1.01 & $38.4 \%$ \\
\hline $\mathrm{Al}-\mathrm{HCl}-\mathrm{H}_{2} \mathrm{O}-\mathrm{BT}-\mathrm{SA}$ & 0.84 & 0.98 & $16.7 \%$ & 0.91 & $8.3 \%$ \\
\hline
\end{tabular}

became faster. We also observed that the deterioration of superhydrophobicity for the $\mathrm{Al}-\mathrm{HCl}-\mathrm{H}_{2} \mathrm{O}$ derived superhydrophobic samples was much slower as compared with the Al-HCl derived superhydrophobic samples. This was mainly because that, for the Al-HCl- $\mathrm{H}_{2} \mathrm{O}$ sample, the micro-steps were covered by nano-flakes. As shown in the equation in Fig. 6f, the resistance to the impact was in inverse proportional to the scale of micro-/nano- structures. In other words, even if the trapped air among the micro-steps was expelled, the trapped air among the nano-flakes might remain stable to slow down the corrosion and the deterioration of superhydrophobicity. For the Al-HCl$\mathrm{H}_{2} \mathrm{O}-\mathrm{BT}-\mathrm{SA}$ sample, it possessed the best corrosion resistance. Even after immersed in the $2 \mathrm{~m} \mathrm{~s}^{-1} \mathrm{NaCl}$ aqueous solution for $50 \mathrm{~h}$, the contact angle for the Al- $\mathrm{HCl}-\mathrm{H}_{2} \mathrm{O}-\mathrm{BT}-\mathrm{SA}$ sample still remained above $150^{\circ}$ (Fig. 6d) and the surface micro-structures were not destroyed obviously (Fig. 6e(iv)).
Hydration of boehmite : $\mathrm{AlO}(\mathrm{OH})+\mathrm{H}_{2} \mathrm{O} \rightarrow \mathrm{Al}(\mathrm{OH})_{3}$

Dissolution of $\mathrm{Al}(\mathrm{OH})_{3}$ :

$$
\begin{aligned}
& \mathrm{Al}(\mathrm{OH})_{3}+\mathrm{Cl}^{-} \rightarrow \mathrm{Al}(\mathrm{OH})_{2} \mathrm{Cl}+\mathrm{OH}^{-} \\
& \mathrm{Al}(\mathrm{OH})_{2} \mathrm{Cl}+\mathrm{Cl}^{-} \rightarrow \mathrm{Al}(\mathrm{OH}) \mathrm{Cl}_{2}+\mathrm{OH}^{-} \\
& \mathrm{Al}(\mathrm{OH}) \mathrm{Cl}_{2}+\mathrm{Cl}^{-} \rightarrow \mathrm{AlCl}_{3}+\mathrm{OH}^{-}
\end{aligned}
$$

Formation of $\mathrm{Al}(\mathrm{OH})_{3}$ :

$$
\begin{aligned}
& 4 \mathrm{Al}+3 \mathrm{O}_{2}+6 \mathrm{H}_{2} \mathrm{O} \rightarrow 4 \mathrm{Al}(\mathrm{OH})_{3} \\
& \mathrm{Al} \rightarrow \mathrm{Al}^{3+}+3 \mathrm{e} \\
& \mathrm{O}_{2}+2 \mathrm{H}_{2} \mathrm{O}+4 \mathrm{e} \rightarrow 4 \mathrm{OH}^{-}
\end{aligned}
$$

The surface chemistry was measured by EDX and the content ratio of oxygen to aluminum, viz., [O]/[Al], was used to estimate the corrosion. ${ }^{38}$ The corrosion process included a series of chemical and electrochemical reactions. Once the water penetrated through the organic layer, the boehmite would be hydrated (eqn (4)) to $\mathrm{Al}(\mathrm{OH})_{3}$, which would further be dissolved gradually under the attack of $\mathrm{Cl}^{-}$anion (eqn (5)). Once the boehmite was dissolved completely, aluminum matrix would be exposed directly to the $\mathrm{NaCl}$ solution and would further be converted to $\mathrm{Al}(\mathrm{OH})_{3}$ through electrochemical corrosion reactions (eqn (6)). Due to the relatively higher oxygen content in the corrosive product of $\mathrm{Al}(\mathrm{OH})_{3}$ as compared with $\mathrm{AlO}(\mathrm{OH})$, after corrosion, the content ratio of oxygen to aluminum, viz., [O]/ [Al], increased (Table 2). The increasing ratio (IR) was simply calculated by the eqn (7)

$$
\mathrm{IR}=\frac{R_{[\mathrm{O}] /[\mathrm{A}]], \mathrm{ac}}-R_{[\mathrm{O}] /[\mathrm{Al}], \mathrm{bc}}}{R_{[\mathrm{O}] /[\mathrm{A}], \mathrm{bc}}}
$$




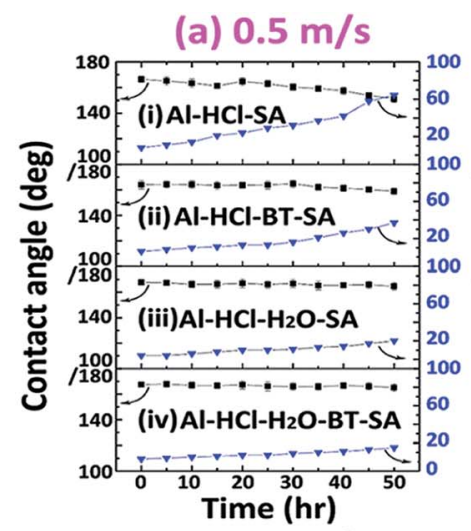

(c) $1.5 \mathrm{~m} / \mathrm{s}$

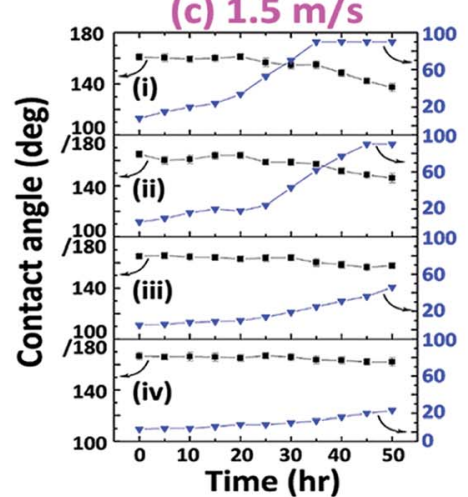

(b) $1.0 \mathrm{~m} / \mathrm{s}$
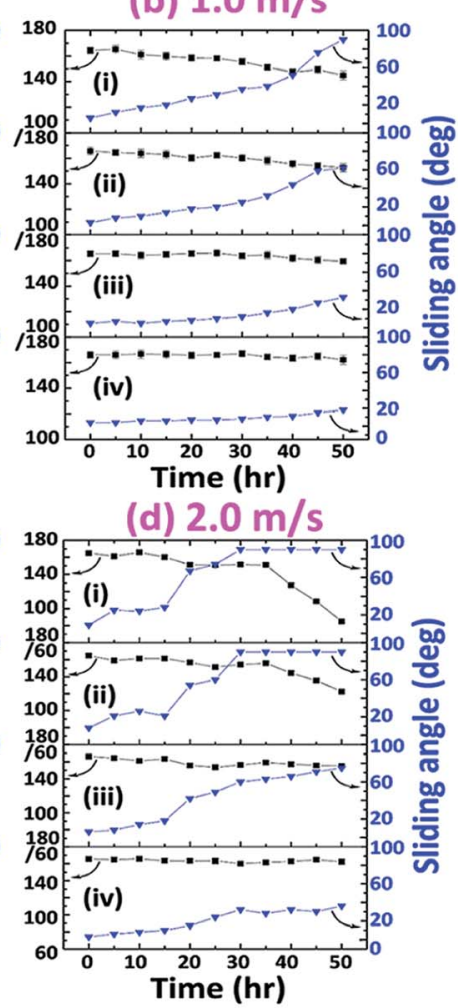
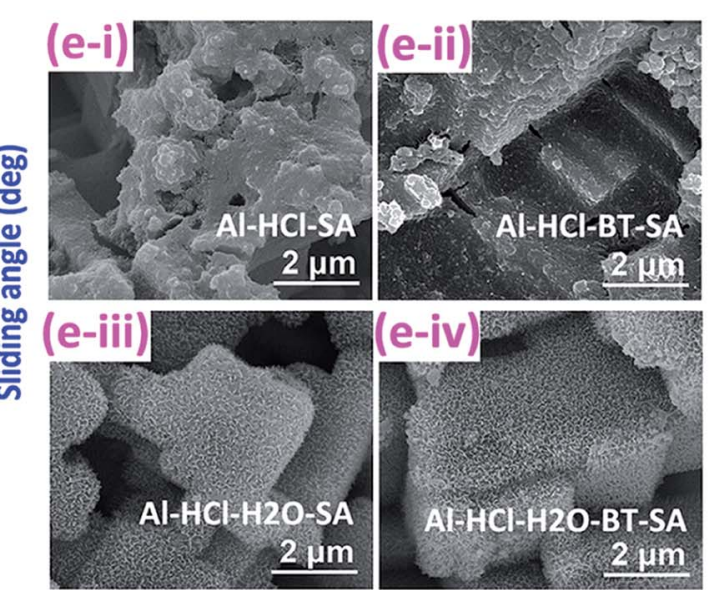

(f)

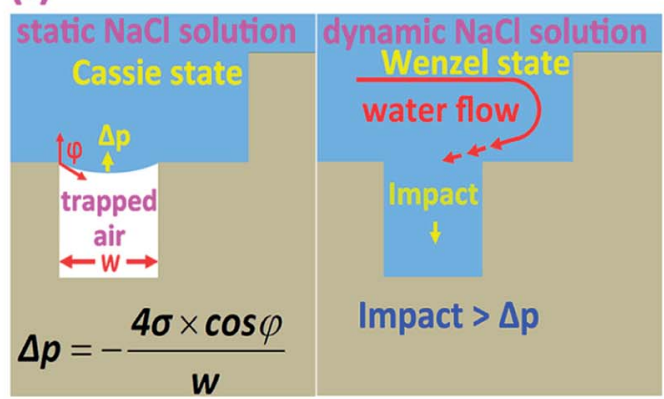

Fig. 6 Variation of surface wettability against immersion time in $\mathrm{NaCl}$ aqueous solution with different flow velocity of $0.5 \mathrm{~m} \mathrm{~s}^{-1}$ (a), $1.0 \mathrm{~m} \mathrm{~s}^{-1}$ (b), $1.5 \mathrm{~m} \mathrm{~s}^{-1}$ (c), and $2.0 \mathrm{~m} \mathrm{~s}^{-1}$ (d). Surface morphology for different sample immersed in $\mathrm{NaCl}$ aqueous solution with the flow velocity of $2.0 \mathrm{~m} \mathrm{~s}{ }^{-1}$ for $50 \mathrm{~h}$ (e). Mechanism for the corrosion resistance of the superhydrophobic surface in the static and the dynamic $\mathrm{NaCl}$ aqueous solution (f).

where $R_{[\mathrm{O}] /[\mathrm{Al}], \mathrm{bc}}$ and $R_{[\mathrm{O}] /[\mathrm{Al}], \text { ac }}$ was the $[\mathrm{O}] /[\mathrm{Al}]$ value before and after corrosion, respectively.

For the Al-HCl derived samples, the oxide layer was removed by $\mathrm{HCl}$ and the oxygen content as expressed by $R_{[\mathrm{O}] /}$ $[\mathrm{A}], \mathrm{bc}$ was much smaller as compared with the $\mathrm{Al}-\mathrm{HCl}-\mathrm{H}_{2} \mathrm{O}$ derived samples. Meanwhile, due to the absence of the barrier oxide layer, after static corrosion for 18 days, the $R_{[\mathrm{O}] /[\mathrm{A}]] \text {,ac }}$ for the Al-HCl-SA sample and the Al-HCl-BT-SA sample increased greatly (Table 2). Specifically, for the Al-HCl-SA sample, the IR value was as high as $2880.0 \%$, which decreased to $1242.9 \%$ once the BT interlayer was added. We also noticed that, the IR values for the $\mathrm{Al}-\mathrm{HCl}-\mathrm{H}_{2} \mathrm{O}$ derived superhydrophobic samples were much smaller than the corresponding $\mathrm{Al}-\mathrm{HCl}$ derived superhydrophobic samples. This suggested that the BT molecules and the boehmite layer could enhance the corrosion resistance of the superhydrophobic sample greatly. Similarly, we found that once the BT molecules or/and oxide layer was added, the IR values in Table 2 decreased greatly. In other words, the BT molecules and oxide layer could retard the corrosion process and consequently the variation in surface chemistry was small. All these findings proved that the oxide layer and BT layer could enhance the corrosion protection in both static and dynamic $\mathrm{NaCl}$ aqueous solution greatly.

\section{Conclusions}

For the first time, the dynamic corrosion of superhydrophobic surface was investigated by monitoring the variation in surface wettability, surface morphology, and surface chemistry. Results showed that, as the flow velocity of $\mathrm{NaCl}$ aqueous solution increased, the corrosion resistance of the Al-HCl$\mathrm{H}_{2} \mathrm{O}$-BT-SA sample deteriorated. This was probably because the retained air layer in the solid/liquid interface was less stable in the dynamic $\mathrm{NaCl}$ aqueous solution. However, compared with the contrast samples, such as the Al-HCl-BTSA sample, the Al-HCl- $\mathrm{H}_{2} \mathrm{O}-\mathrm{SA}$ sample, and the Al-HCl-SA sample, the deterioration in dynamic corrosion resistance for the Al-HCl- $\mathrm{H}_{2} \mathrm{O}-\mathrm{BT}-\mathrm{SA}$ sample was much lower. This suggested that the dynamic corrosion of superhydrophobic surface was closely related with the micro-structures and the organic passivated layer. To sum up, as the water flow velocity increased, the corrosion resistance of the superhydrophobic surface indeed deteriorated; however, by rational surface designing (such as the surface structures with smaller dimension and the passivated layer with better corrosion resistance), such deterioration could be slowed down. The present study therefore provided a fundamental understanding for the applications of superhydrophobic samples to prevent the corrosion, especially, for various vessels in dynamic water. 


\section{Conflicts of interest}

There are no conflicts to declare.

\section{Acknowledgements}

The authors acknowledge with pleasure the financial support of this work by the National Natural Science Foundation of China (Grant No. 51563018 and 51463018) and the Qing Lan Project of Jiangsu province.

\section{References}

$1 \mathrm{~W}$. Li, C. Thomas and M. Arumugam, Activation of aluminum as an effective reducing agent by pitting corrosion for wet-chemical synthesis, Sci. Rep., 2013, 3, 1229.

2 S. S. A. Rehim, H. H. Hassan and M. A. Amin, Corrosion and corrosion inhibition of $\mathrm{Al}$ and some alloys in sulphate solutions containing halide ions investigated by an impedance technique, Appl. Surf. Sci., 2002, 187, 279-290.

3 M. A. Amin, S. S. Abd El-Rehim, E. E. F. El-Sherbini, S. R. Mahmoud and M. N. Abbas, Pitting corrosion studies on $\mathrm{Al}$ and $\mathrm{Al}-\mathrm{Zn}$ alloys in SCN- solutions, Electrochim. Acta, 2009, 54, 4288-4296.

4 M. A. Amin, Metastable and stable pitting events on $\mathrm{Al}$ induced by chlorate and perchlorate anions-polarization, XPS and SEM studies, Electrochim. Acta, 2009, 54, 1857-1863.

5 M. A. Amin, S. S. Abd El Rehim and A. S. El-Lithy, Pitting and pitting control of $\mathrm{Al}$ in gluconic acid solutions-polarization, chronoamperometry and morphological studies, Corros. Sci., 2010, 52, 3099-3108.

6 M. A. Amin, S. S. Abd El Rehim and A. S. El-Lithy, Corrosion, passivation and breakdown of passivity of $\mathrm{Al}$ and $\mathrm{Al}-\mathrm{Cu}$ alloys in gluconic acid solutions, Electrochim. Acta, 2010, 55, 59966003.

7 H. J. W. Lenderink, M. V. D. Linden and J. H. W. De Wit, Corrosion of aluminum in acidic and neutral solutions, Electrochim. Acta, 1993, 38, 1989-1992.

8 J. Zhao, L. Xia, A. Sehgal, D. Lu, R. L. McCreery and G. S. Frankel, Effects of chromate and chromate conversion coatings on corrosion of aluminum alloy 2024T3, Surf. Coat. Technol., 2001, 140, 51-57.

9 E. Rudolf and M. Cervinka, Nickel modifies the cytotoxicity of hexavalent chromium in human dermal fibroblasts, Toxicol. Lett., 2010, 197, 143-150.

10 J. Qi, B. Zhang, Z. Wang, Y. Li, P. Skeldon and G. E. Thompson, Effect of an Fe(II)-modified trivalent chromium conversion process on $\mathrm{Cr}(\mathrm{VI})$ formation during coating of AA 2024 alloy, Electrochem. Commun., 2018, 92, $1-4$.

11 T. F. Child and W. J. Van Ooij, Application of silane technology to prevent corrosion of metals and improve paint adhesion, Trans. IMF, 1999, 77, 64-70.

12 Y. H. Li, X. H. Jin and J. M. Hu, Electrodeposited silica films post-treated with organosilane coupling agent as the pretreatment layers of organic coating system, Corros. Sci., 2016, 106, 127-136.
13 L. Giraud, R. Nadarajah, Y. Matar, G. Bazin, J. Sun, X. X. Zhu and S. Giasson, Amino-functionalized monolayers covalently grafted to silica-based substrates as a robust primer anchorage in aqueous media, Appl. Surf. Sci., 2016, 370, 476-485.

14 E. Asenath-Smith and W. Chen, How to prevent the loss of surface functionality derived from aminosilanes, Langmuir, 2008, 24, 12405-12409.

15 M. Zhu, M. Z. Lerum and W. Chen, How to prepare reproducible, homogeneous, and hydrolytically stable aminosilane-derived layers on silica, Langmuir, 2012, 28, 416-423.

16 M. Etienne and A. Walcarius, Analytical investigation of the chemical reactivity and stability of aminopropyl-grafted silica in aqueous medium, Talanta, 2003, 59, 1173-1188.

17 M. G. S. Ferreira, R. G. Duarte, M. F. Montemor and A. M. P. Simoes, Silanes and rare earth salts as chromate replacers for pre-treatments on galvanised steel, Electrochim. Acta, 2004, 49, 2927-2935.

18 W. Trabelsi, P. Cecilio, M. G. S. Ferreira and M. F. Montemor, Electrochemical assessment of the selfhealing properties of Ce-doped silane solutions for the pretreatment of galvanised steel substrates, Prog. Org. Coat., 2005, 54, 276-284.

19 W. Xiao, R. L. Man, C. Miao and T. L. Peng, Study on corrosion resistance of the BTESPT silane cooperating with rare earth cerium on the surface of aluminum-tube, J. Rare Earths, 2010, 28, 117-122.

20 M. F. Montemor, W. Trabelsi, S. V. Lamaka, K. A. Yasakau, M. L. Zheludkevich, A. C. Bastos and M. G. S. Ferreira, The synergistic combination of bis-silane and $\mathrm{CeO}_{2} \cdot \mathrm{ZrO}_{2}$ nanoparticles on the electrochemical behaviour of galvanised steel in NaCl solutions, Electrochim. Acta, 2008, 53, 5913-5922.

21 Y. P. Zhang, H. Z. Zhu, C. Zhuang, S. G. Chen, L. Q. Wang, L. H. Dong and Y. S. Yin, $\mathrm{TiO}_{2}$ coated multi-wall carbon nanotube as a corrosion inhibitor for improving the corrosion resistance of BTESPT coatings, Mater. Chem. Phys., 2016, 179, 80-91.

22 S. G. Chen, Y. C. Cai, C. Zhuang, M. Y. Yu, X. W. Song and Y. P. Zhang, Electrochemical behavior and corrosion protection performance of bis-[triethoxysilylpropyl] tetrasulfide silane films modified with $\mathrm{TiO}_{2}$ sol on 304 stainless steel, Appl. Surf. Sci., 2015, 331, 315-326.

23 K. Yin, S. Yang, X. R. Dong, D. K. Chu, J. A. Duan and J. He, Robust laser-structured asymmetrical PTFE mesh for underwater directional transportation and continuous collection of gas bubbles, Appl. Phys. Lett., 2018, 112, 243701.

24 K. Yin, D. K. Chu, X. R. Dong, C. Wang, J. A. Duan and J. He, Femtosecond laser induced robust periodic nanoripples structured mesh for highly efficient oil-water separation, Nanoscale, 2017, 9, 14229-14235.

25 J. Li, X. G. Bai, X. H. Tang, F. Zha, H. Feng and F. Qi, Underwater superoleophobic/underoil superhydrophobic corn cob coated meshes for on-demand oil/water separation, Sep. Purif. Technol., 2018, 195, 232-237. 
26 J. Li, C. C. Xu, C. Q. Guo, H. F. Tian, F. Zha and L. Guo, Underoil superhydrophilic desert sand layer for efficient gravity-directed water-in-oil emulsions separation with high flux, J. Mater. Chem. A, 2018, 6, 223-230.

27 T. Liu, S. Chen, S. Cheng, J. Tian, X. Chang and Y. Yin, Corrosion behavior of super-hydrophobic surface on copper in seawater, Electrochim. Acta, 2007, 52, 8003-8007.

28 D. W. Zhang, L. T. Wang, H. C. Qian and X. G. Li, Superhydrophobic surfaces for corrosion protection: a review of recent progresses and future directions, J. Coat. Technol. Res., 2016, 13, 11-29.

29 D. W. Zhang, H. C. Qian, L. T. Wang and X. G. Li, Comparison of barrier properties for a superhydrophobic epoxy coating under different simulated corrosion environments, Corros. Sci., 2016, 103, 230-241.

30 L. B. Boinovich, S. V. Gnedenkov, D. A. Alpysbaeva, V. S. Egorkin, A. M. Emelyanenko, S. L. Sinebryukhov and A. K. Zaretskaya, Corrosion resistance of composite coatings on low-carbon steel containing hydrophobic and superhydrophobic layers in combination with oxide sublayers, Corros. Sci., 2012, 55, 238-245.

31 L. B. Boinovich, E. B. Modin, A. R. Sayfutdinova, K. A. Emelyanenko, A. L. Vasiliev and A. Emelyanenko, Combination of functional nanoengineering and nanosecond laser texturing for design of superhydrophobic aluminum alloy with exceptional mechanical and chemical properties, ACS Nano, 2017, 11, 10113-10123.

32 B. Qian and Z. Shen, Fabrication of superhydrophobic surfaces by dislocation-selective chemical etching on aluminum, copper, and zinc substrates, Langmuir, 2005, 21, 9007-9009.

33 W. Wu, X. Wang, D. Wang, M. Chen and F. Zhou, Alumina nanowire forests via unconventional anodization and super-repellency plus low adhesion to diverse liquids, Chem. Commun., 2009, 9, 1043-1045.

34 J. F. Ou, W. H. Hu, M. S. Xue, F. J. Wang and W. Li, Superhydrophobic surfaces on light alloy substrates fabricated by a versatile process and their corrosion protection, ACS Appl. Mater. Interfaces, 2013, 5, 3101-3107.

35 Y. Q. Wen, H. M. Meng and W. Shang, Corrosion resistance and adsorption behavior of bis-( $\gamma$-triethoxysilylpropyl)tetrasulfide self-assembled membrane on 6061 aluminum alloy, RSC Adv., 2015, 5, 80129-80135.

36 J. Kim, P. C. Wong, K. C. Wong, R. N. S. Sodhi and K. A. R. Mitchell, Adsorption of BTSE and $\gamma$-GPS organosilanes on different microstructural regions of 7075T6 aluminum alloy, Appl. Surf. Sci., 2007, 253, 3133-3143.

37 A. M. Cabral, R. G. Duate, M. F. Montemor and M. G. S. Ferreira, A comparative study on the corrosion resistance of AA2024-T3 substrates pre-treated with different silane solutions: Composition of the films formed, Prog. Org. Coat., 2005, 54(4), 322-331.

38 D. M. Lv, J. F. Ou, M. S. Xue and F. J. Wang, Stability and corrosion resistance of superhydrophobic surface on oxidized aluminum in $\mathrm{NaCl}$ aqueous solution, Appl. Surf. Sci., 2015, 333, 163-169. 